\title{
COMPORTAMENTO DE ESPÉCIES DE MERCÚRIO NO SISTEMA SEDIMENTO-ÁGUA DO MANGUE NO MUNICÍPIO DE CUBATÃO, SÃO PAULO
}

\author{
Raphael Hypolito $^{1}$, Luciana Maria Ferrer ${ }^{1}$ e Silvia Cremonez Nascimento ${ }^{1}$
}

Recebido em 16/04/2004, aceito em 25/09/2004

\begin{abstract}
RESUMO A área de estudo encontra-se degradada especialmente devido o lançamento contínuo de efluentes na Baía de Santos, Rios Cubatão, Mogi etc. com fontes difusas de emissão de mercúrio, além da ocupação urbana e industrial, muito próximas. Uma vez detectada a presença de mercúrio no estuário, foram efetuadas caracterizações texturais, mineralógicas e químicas com levantamentos de parâmetros físico-químicos locais, objetivando o estudo do comportamento do mercúrio nesse ambiente. Valores de potencial de óxido-redução, presença de pirita e matéria orgânica indicam estabilidade do mercúrio principalmente sob a forma de $\mathrm{Hg}_{(\mathrm{aq})}^{0}$ e de $\mathrm{HgS}$. As cargas superficiais negativas das partículas coloidais dos argilominerais facilitam a adsorção de mercúrio iônico e/ou complexado. O mercúrio acha-se associado à matéria-orgânica nos sedimentos enquanto nos lodos é praticamente nula a influência em seu comportamento. Os óxidos-hidróxidos (Fe e $\mathrm{Al}$ ) pouco contribuem para a fixação do mercúrio nos sedimentos, mas são decisivos nos lodos. A força iônica influi na mobilidade do mercúrio apenas nos locais sujeitos à variação da maré.
\end{abstract}

Palavras-chave: mercúrio, solos, sedimentos, águas superficiais, águas subterrâneas.

\begin{abstract}
The study area is specially degraded due to the continuous release of effluent in the Santos Bay, Cubatão, Mogi Rivers etc. coming from diffuse sources of mercury emission, besides the urban and industrial very close occupation. Once presence of the mercury was detected in the estuary, characterization grains size, mineralogical and chemical with survey physical-chemical parameters, in order to determine the behavior of the mercury in this environment. Value of oxidereduction potential, pyrite presence and organic matter indicated mercury stability under the form of $\mathrm{Hg}^{0}{ }_{(\mathrm{aq})}$ and of $\mathrm{HgS}$. The negatives superficial loads of the coloidal particles to the clay minerals facilitate the adsorption of mercury ionic and/or complex. The mercury is associate to the organic matter in the sediments and in the muds it has practically null the influence in your behavior. The oxide-hydroxides ( $\mathrm{Fe}$ and $\mathrm{Al}$ ) have a low contribution to the mercury fixation in the sediments, but they are decisive in the muds. The ionic strength just influences on the mobility of the mercury in the places subjects to the variation of the tide.
\end{abstract}

Keywords: mercury, soils, sediments, superficial water, groundwater.

\section{INTRODUÇÃO}

O mercúrio é, de modo geral, introduzido no meio ambiente através de atividades antrópicas de diversas naturezas e sua interferência no ecossistema ocorre quando é incorporado na cadeia trófica.

$\mathrm{Na}$ forma metálica ele fica sendo disponível para diferentes reações químicas, biológicas e fotoquímicas (KAISER; TÖLG, 1980) podendo tornar-se bastante estável.

No meio natural, a forma mais abundante do mercúrio é representada pelo cinábrio $(\mathrm{HgS})$ de onde é extraído. No Brasil sua produção é realizada somente através de fontes secundárias a partir de resíduos industriais e sucatas.

Estima-se, através do consumo para as diversas atividades, que do total de mercúrio metálico importado, são perdidos mais de 360 toneladas e não recuperados cerca de $60 \%$. As principais perdas concentram-se nas atividades garimpeiras $(80 \%)$ e, em segundo lugar, surgem as indústrias de clorosoda com $8 \%$ de perdas. Na indústria de cloro-soda, que utiliza no processo produtivo células eletrolíticas, as perdas se distribuírem essencialmente no sistema de salmoura (60\%), no ar da sala das células $(25 \%)$, no hidrogênio (4\%), na lixívia (1\%) e outras formas diversas (10\%) (FERREIRA; APPEL apud MASTER, 1989).

A utilização de novos processos de produção, entretanto, representados pela tecnologia de células de membrana e de células de diafragma de amianto, tem diminuído o consumo de mercúrio na produção de cloro e soda. Uma das emissões do mercúrio para a atmosfera, resultado de atividades antropogênicas, é responsável por valores que oscilam de 20 a $60 \%$ de sua emissão total (NIAGRU, 1990; WILKEN; HINTELMANN, 1990).

Uma vez no meio aéreo, com a precipitação meteórica, o mercúrio é incorporado ao sistema aquático e, dependendo das condições do sistema, por exemplo, se o meio for ácido, pode ocorrer formação de monometilmercúrio, forma na qual penetra facilmente nas membranas celulares e entra na cadeia trófica.

\footnotetext{
${ }^{1}$ Depto. de Geologia Sedimentar e Ambiental e Centro de Pesquisa de Águas Subterrâneas - Instituto de Geociências - USP (raphael.hypolito@br2001.com.br),(luciana.ferrer@creasp.org.br),( scremo@usp.br)
} 
O tempo de residência dos compostos de mercúrio no ar é relatado por KOTHNY (1993) como sendo de 3 meses, contudo, há evidências que este tempo não chega a ultrapassar apenas alguns dias (LINDQVIST; RHODE, 1985).

$\mathrm{O}$ mercúrio tem a possibilidade de ser transportado a longas distâncias pela atmosfera, fato comprovado pela medição de concentrações incompatíveis quando comparados aos teores das fontes mais próximas, em locais isolados como o Ártico (SCHROEDER; SCHNEEBERGER, 1996).

Estudos na região de Poconé, como exemplo, correlacionando seu transporte pelas correntes de ar segundo a direção dos ventos dominantes, demonstraram que o $\mathrm{Hg}$ no estado gasoso foi transposto a um raio de até 400 metros a partir do ponto de queima de amálgamas (CETEM, 1989).

As condições de $\mathrm{pH}$, potencial de óxidoredução, concentração de ânions e quantidade de matéria orgânica, de maneira geral, ditam a natureza das espécies de mercúrio e sua distribuição nos ambientes aquáticos.

Um aspecto importante da presença de mercúrio no meio aquático refere-se à possibilidade de transformação do metal em compostos metilados, muito mais tóxicos. O metilmercúrio é formado pelo íon mercúrio por reação a nível enzimático e/ou por reações sob condições aeróbias e anaeróbias (HUGUNIN e BRADLEY apud REEDER et al., 1979). Por outro lado, junto aos materiais sólidos, a riqueza de matéria orgânica, associada à presença de altos teores de argila, assim como condições de alta salinidade, como é o caso dos manguezais, levam a um comportamento bastante complexo das espécies de mercúrio. Esta afirmação vem corroborar com o interesse do estudo na região de mangue em Cubatão, notadamente reiterando o fato de que emissões antropogênicas de resíduos mercuriais foram detectadas no local em tempos pretéritos.

O ambiente escolhido para estudo diz respeito ao mangue localizado nas circunvizinhanças do Complexo Industrial de Cubatão, situado em locais onde ocorrem condições naturais que facilitam acúmulo de metais através de emissões de mercúrio por indústrias produtoras de clorosoda junto à foz do Rio Cubatão.

Deve-se levar em conta ainda o número relativamente elevado de famílias que se instalam próximas à esta porção do manguezal, uma vez que a área encontra-se na região limítrofe entre a cidade de Cubatão e o Pólo Industrial ali instalado.
Finalmente, medições de $\mathrm{Hg}_{(t)}$ nas estações de estudos na região da Baixada Santista, verificouse que, em 1998, 64\% das estações do Estuário de Santos os teores apresentavam valores oito vezes superiores ao limite recomendado para preservação da vida aquática $\left(0,10 \mathrm{mg} \cdot \mathrm{L}^{-1}\right)$ (CETESB, 1998). E nas estações de amostragem do Rio Cubatão os resultados apresentaram valores de $0,98 \mathrm{mg} \cdot \mathrm{dm}^{-3}$ nos sedimentos de corrente. Estes dados chamaram a atenção e contribuíram com mais um motivo para que se estudasse o comportamento do mercúrio neste ambiente.

\section{ÁREA DE ESTUDO}

Mangues ou manguezais são ambientes costeiros situados na faixa de maré, onde habitam várias espécies de peixes, crustáceos e aves, além de vegetações características. É um local que possui comunidades costeiras tropicais dominadas por espécies vegetais, arbóreas ou arbustivas que conseguem crescer em solos com alto teor de sal. Seu solo é uma espécie de lama escura e mole.De modo geral, o manguezal ocupa todas as regiões de costas protegidas, sendo ausente somente nas praias rochosas e arenosas abertas.

No passado, a extensão dos manguezais brasileiros era muito mais ampla; atualmente diminuiu sensivelmente, graças à ocupação antrópica, com construção de portos, moradias, balneários e rodovias costeiras, que avançou sobre áreas de manguezal através da instalação de aterros e outras obras de terraplenagem.

A importância desses ecossistemas pode ser avaliada por seu trabalho de proteção contra ações erosivas das ondas e marés, fixação dos sedimentos finos e pela ação como filtro biológico natural.

A importância social dos manguezais pode, por outro lado, ser estimada muitas vezes pela presença de comunidades pesqueiras que deles extraem alimentação, moradia e renda.

A região de estudo está localizada no município de Cubatão, litoral sudeste do Brasil, descrito como um ecossistema costeiro incluído na Sub-unidade da Baixada Santista, sendo o Litoral Norte e Litoral Sul as outras duas Subunidades (CETESB, 1998).

Em área, o manguezal de Cubatão é o segundo maior da região da Baixada Santista com $23 \mathrm{~km}^{2}$ perdendo somente para Santos.

Com relação à qualidade ambiental do litoral paulista, a região da Baixada Santista é, sem dúvida, a que apresenta o maior grau de 
degradação, em função da ocupação humana e do complexo industrial e portuário. A região de estudo fica bastante próxima ao centro urbano e ao Complexo Industrial de Cubatão; este foi um dos fatores que despertaram interesse para a realização de investigações com o mercúrio e também o fato deste elemento ser detectado em padrões ambientais inadequados pelo órgão estadual de fiscalização perto do local.

A região possui altos índices pluviométricos, principalmente nos meses de verão, variando de 2000 a $2500 \mathrm{~mm}$, apresentando clima quente e úmido e temperatura média anual superior a $20^{\circ} \mathrm{C}$ (SANTOS apud CETESB, 1998).

\section{MATERIAL E MÉTODOS}

Os trabalhos de campo consistiram na caracterização geológica no local de coleta de amostras de sedimentos lodos e águas (superficiais e subterrâneas). Na Figura 1 tem-se mapa da área de estudo e a localização dos 12 pontos de amostragens. Durante os procedimentos de amostragens foram medidos in situ parâmetros físico-químicos como $\mathrm{pH}$, Eh, condutividade elétrica (CE), alcalinidade, sólidos totais dissolvidos e temperatura.

Para a caracterização da condição atual do mercúrio foram coletadas nos meses mais secos do ano, quando foi possível o acesso ao local de estudo.

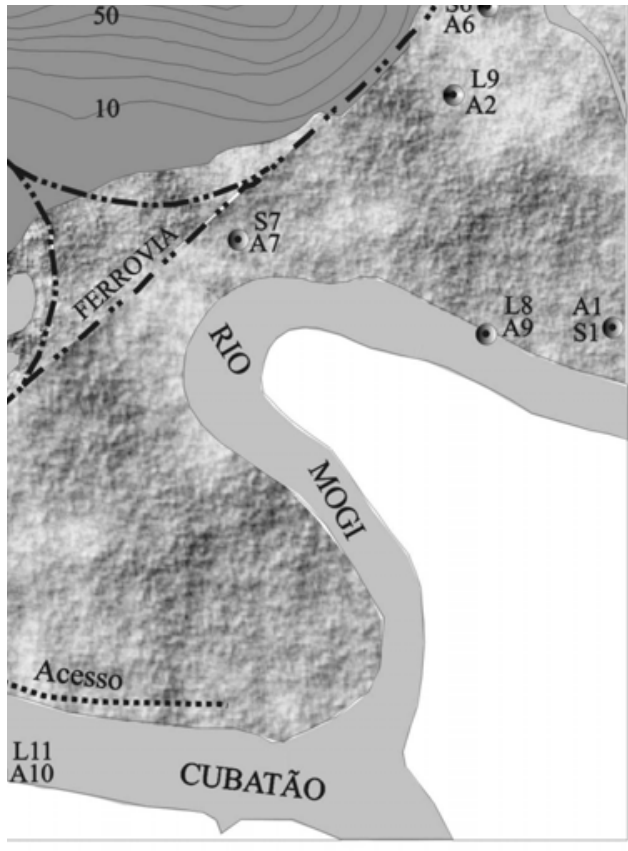

\section{OS RIOS CUBATÃO E MOGI}

\section{GEOLGIA E LOCALIZAČ̃̃O DOS}

PONTOS DE AMOSTRAGEM DE ÁGUAS, LODOS E SEDIMENTOS

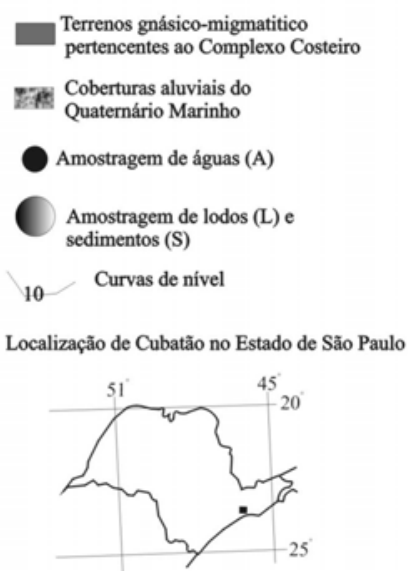

Base:IGc, Folha Topográfica Cubatão Escala 1:10.000, 1987

Figura 1 - Área de estudo e pontos de amostragem

Foram realizadas sondagens com trado tipo helicoidal $(\varnothing=15 \mathrm{~cm})$ com coleta de amostras de sedimento. Eram esperadas coletas a cada variação litológica significativa de cor, granulometria ou outros aspectos texturais e estruturais significativos. $\mathrm{O}$ sedimento, no entanto, apresentou-se homogêneo em todo o perfil, o que levou a amostragens compostas formadas pela mistura daquelas obtidas no perfil.

Devido à dificuldade imposta pelos terrenos lodosos e sistematicamente inundados, as amostras dos diferentes pontos nem sempre foram obtidas nas mesmas profundidades. As escavações a trado foram limitadas quando do colapso das paredes do furo. Também a rápida infiltração de água durante as perfurações, variável para cada ponto, contribuiu para dificultar a coleta tornando-a bastante difícil e limitada. Desta forma, foram frustradas as tentativas de coletas em períodos chuvosos como seria também desejável.

As amostras dos terrenos, por se apresentarem periodicamente alagados, foram de difícil acondicionamento e preservação de estruturas primárias e cada porção do sedimento coletado numa mesma sondagem foi isolada das demais através de sacos plásticos hermeticamente fechados. Este procedimento é umas das poucas formas de se manter representativo o sedimento do local amostrado. 
Com amostras de sedimento efetuaram-se análises por difratometria de raios $\mathrm{X}$ e análises laboratoriais de naturezas variadas.

A coleta de águas superficiais deu-se por garrafa amostradora de construção caseira, tendose o cuidado de, à cada nova amostragem, realizar-se a limpeza do coletor de amostra com água deionizada e lavada com a própria água do local.

As amostras de água (tanto superficiais quanto subterrâneas) foram filtradas in situ em membrana de acetato de celulose de $0,45 \mu \mathrm{m}$ acondicionadas em frascos de polietileno. Parte foi resfriada a temperatura inferior à $4{ }^{\circ} \mathrm{C}$ para análises de ânions e testemunho e parte acidulada com $\mathrm{HNO}_{3}(8 \mathrm{M})$ até $\mathrm{pH}$ menor que 2 e destinada às análises por espectrofotometria de absorção atômica.

Foram realizadas medições de $\mathrm{pH}$ e Eh e a condutividade elétrica foi medida, com sensor de temperatura estabilizado em $25^{\circ} \mathrm{C}$.

A alcalinidade foi medida no campo, através de titulação com $\mathrm{H}_{2} \mathrm{SO}_{4}$ (HYPOLITO, 2004) e as medições do nível da água, quando este não era aflorante à superfície do terreno, foram realizadas através de medidor manual elétrico com dispositivo luminoso.

\section{MEDIDAS EM CAMPO pH, Eh e CE}

A maior parte da área de estudo é periodicamente inundada, intensificada nos períodos chuvosos, difícultando e mesmo, por vezes, impossibilitando o acesso para coletas de amostras de águas subterrâneas. A medição dos parâmetros físico-químicos foi obtida in situ nos períodos mais secos do ano, nos meses de julho e agosto.

A maior parte da área de estudo é periodicamente inundada, intensificada nos períodos chuvosos, dificultando e mesmo, por vezes, impossibilitando o acesso para coletas de amostras de águas subterrâneas. A medição dos parâmetros físico-químicos foi obtida in situ nos períodos mais secos do ano, nos meses de julho e agosto.

Foram medidos potenciometricamente os valores de $\mathrm{pH}$ e Eh respectivamente com eletrodo de vidro e combinado de platina (DM 2-Digimed e Metrohm-EA-121).

As condutividades elétricas das águas foram determinadas com Condutivímetro modelo DM3.

As amostras de águas (superficiais e subterrâneas) são de naturezas distintas, provenientes dos rios Cubatão e Mogi e da região de inundação do mangue. A Tabela 1 ilustra as medições realizadas nos pontos de coleta de água.

A alcalinidade, apesar de ser determinada nos trabalhos de campo, apresentou valores pouco confiáveis, uma vez que as amostras com cor fortemente acastanhadas dificultou muito a observação do ponto de viragem.

\section{TRABALHOS LABORATORIAIS}

Análises Mineralógicas e Granulométricas /Texturais

As amostras de sedimentos foram analisadas por difratometria de raios $\mathrm{X}$ utilizando difratômetro SIEMENS D-5000, com identificação mineralógica Eva 2.0.

As análises granulométricas/texturais quantitativas foram determinadas com amostras de sedimentos após ataque com água oxigenada para destruição da matéria orgânica, secos ao ar, peneirados e dispersados com pirofosfato de sódio. A seguir, pelo método da "Pipeta de Robinson", foram separadas frações entre 0,002 $\mathrm{mm}$ (argila) e de 0,002 a $0,02 \mathrm{~mm}$ (silte fino). As frações superiores a $0,02 \mathrm{~mm}$ são determinadas por peneiramento a seco. As porcentagens de areia, silte e argila são apresentadas na tabela 2 .

\section{Determinação de pH do sedimento (S) e lodo} (L)

Para se determinarem as condições de cargas expostas nas frações menores que $2 \mathrm{~mm}$ do sedimento e lodo, efetuaram-se medidas de $\mathrm{pH}$ em $\mathrm{H}_{2} \mathrm{O}$ e em solução de $\mathrm{KCl}$.Na tabela 3 encontram-se os resultados obtidos, bem como os valores de $\Delta p H\left(\mathrm{pH}_{\mathrm{H} 2 \mathrm{o}}-\mathrm{pH}_{\mathrm{H} 2 \mathrm{o} / \mathrm{KCl}}\right)$.

Tabela 1 - Parâmetros medidos nos pontos de coleta de amostras de águas (A) da área de estudo

\begin{tabular}{cccc}
\hline $\begin{array}{c}\text { Pontos de } \\
\text { amostragem }\end{array}$ & $\mathbf{p H}$ & $\begin{array}{c}\text { Eh } \\
(\mathbf{V})\end{array}$ & $\begin{array}{c}\mathbf{C E . 1 0 ^ { 3 }} \\
\left(\boldsymbol{\mu} \mathbf{S} . \mathbf{c m}^{-1}\right)\end{array}$ \\
\hline A1 & 4,54 & $+0,13$ & 17,03 \\
A2 & 4,97 & $+0,19$ & 14,12 \\
A3 & 4,33 & $+0,18$ & 12,41 \\
A4 & 3,30 & $+0,22$ & 19,33 \\
A5 & 5,95 & $+0,02$ & 93,18 \\
A6 & 6,19 & $+0,04$ & 8,51 \\
A7 & 5,84 & $+0,05$ & 5,43 \\
A8 & 6,64 & $+0,01$ & 3,51 \\
A9 & 6,91 & $+0,02$ & 1,28 \\
A10 & 4,98 & $+0,12$ & 0,61 \\
\hline
\end{tabular}


Tabela 2 - Teores (\%) de areia, silte e argila das amostras de sedimento (S) e lodo (L) segundo a profundidade de coleta $(\mathrm{cm})$.

\begin{tabular}{ccccc}
\hline Amostra & Prof. & Areia & Silte & Argila \\
\hline S1 & 10 & 23,94 & 57,28 & 18,78 \\
S1 & 30 & 27,53 & 56,71 & 15,75 \\
S1 & 80 & 34,13 & 44,42 & 21,45 \\
S2 & 20 & 79,20 & 8,79 & 12,01 \\
S2 & 60 & 75,56 & 10,74 & 13,70 \\
S2 & 30 & 68,64 & 13,27 & 18,09 \\
S3 & 50 & 57,26 & 8,45 & 24,28 \\
S3 & 70 & 76,80 & 12,51 & 10,68 \\
S3 & 80 & 79,70 & 10,48 & 9,83 \\
S3 & 100 & 56,30 & 36,39 & 7,31 \\
S4 & 40 & 63,49 & 29,69 & 6,82 \\
S4 & 80 & 50,67 & 38,75 & 10,58 \\
S4 & 100 & 67,80 & 25,11 & 7,08 \\
S5 & 30 & 45,61 & 41,13 & 13,25 \\
S5 & 60 & 46,63 & 40,10 & 13,27 \\
S5 & 90 & 55,39 & 32,76 & 11,85 \\
S5 & 100 & 61,13 & 23,15 & 15,72 \\
S6 & 150 & 49,10 & 30,60 & 11,30 \\
S7 & 150 & 46,70 & 40,91 & 12,39 \\
\hline
\end{tabular}

Tabela 3 - Valores de pH para sedimentos (S) e lodos (L) e respectivos $\Delta \mathrm{pH}$.

\begin{tabular}{c|c|c|c}
\hline $\begin{array}{c}\text { Amostras de } \\
\text { sedimentos (S) } \\
\text { e lodos (L) }\end{array}$ & $\mathbf{p H}_{\mathbf{H} 2 \mathbf{O}}$ & $\mathbf{p H}_{\mathbf{K C l}}$ & $\Delta \mathbf{p H}$ \\
\hline S1 & 4,40 & 3,30 & $+1,10$ \\
S2 & 3,71 & 3,08 & $+0,63$ \\
S3 & 3,91 & 3,11 & $+0,80$ \\
S4 & 4,33 & 3,24 & $+1,09$ \\
S5 & 4,87 & 1,92 & $+2,95$ \\
S6 & 3,54 & 3,24 & $+0,30$ \\
S7 & 4,11 & 3,61 & $+0,50$ \\
L8 & 4,27 & 3,63 & $+0,64$ \\
L9 & 3,87 & 3,52 & $+0,35$ \\
L10 & 5,76 & 5,02 & $+0,74$ \\
L11 & 2,22 & 2,10 & $+0,12$ \\
L12 & 5,82 & 4,95 & $+0,87$ \\
\hline
\end{tabular}

\section{Extrações iônicas em amostras de sólidos}

Por ser de grande interesse neste trabalho os fenômenos referentes à adsorção de mercúrio associado aos constituintes dos sedimentos e lodos foram efetuadas extrações em condições brandas, parciais, com água e enérgicas, totais, com $\mathrm{HNO}_{3}(8 \mathrm{M})$.
As extrações com água e com solução nítrica, possibilitaram, respectivamente, separação dos íons livres, hidratados contidos nas soluções intersticiais, assim como os adsorvidos nos diferentes sítios de adsorção das partículas sólidas (sedimento/lodo).

$\mathrm{O}$ mercúrio, pelos procedimentos analíticos convencionais, é um elemento de difícil determinação analítica. Os equipamentos utilizados, em geral, apresentam limite de deteç̧ão na ordem de $0,001 \mathrm{mg} \cdot \mathrm{dm}^{-3}$. A importância de se conhecerem as concentrações traço, da ordem de $\mu \mathrm{g} . \mathrm{dm}^{-3}$, está associada à periculosidade de sua dispersão no meio físico, uma vez que é comprovada sua elevada toxicidade.

Análises químicas de mercúrio em amostras das frações superiores a $2 \mathrm{~mm}$ submetidas a ataque ácido enérgico $\left(\mathrm{HNO}_{3} / \mathrm{HCl}\right)$ revelaram ausência de mercúrio. Desta forma, foi utilizada, para as caracterizações químicas, mineralógicas e texturais, somente a frações menores que $2 \mathrm{~mm}$. Nestas frações tem-se como constituintes principais quartzo (capeado por óxidos e hidróxidos), argilominerais e óxidos/ hidróxidos de ferro, alumínio, manganês e matéria orgânica.

O tratamento com água possibilitou análise dos íons existentes em solução, nos interstícios dos grãos de sedimentos e lodos; neste caso tratase dos íons solúveis; por outro lado, a extração com $\mathrm{HNO}_{3}$ libera o mercúrio associado especialmente a óxidos-hidróxidos de ferro, alumínio e manganês.

Em testes prévios as amostras de sedimentos mostraram-se, nos perfis, isentas de mercúrio e concentrações pouco significativas com algumas variações nos teores de sódio abaixo do nível da água. Assim sendo, para a realização das extrações optou-se por análises químicas de amostras compostas, constituídas por frações quarteadas de cada ponto.

Os resultados analíticos dos sedimentos e lodos, somente dos cátions de interesse para o trabalho encontram-se respectivamente nas tabelas 4 a 7 .

A profundidade de coleta de mostras de lodo foi padronizada em $20 \mathrm{~cm}$ para todos os pontos localizados às margens dos Rios Cubatão e Mogi. 


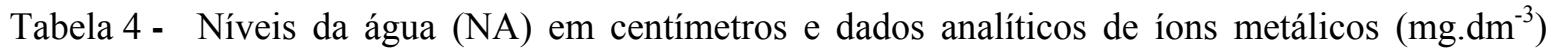
extraídos com água das amostras compostas de sedimento.

\begin{tabular}{c|c|c|c|c|c}
\hline Amostra & $\mathbf{N a}^{+}$ & $\mathbf{K}^{+}$ & $\mathbf{F e}_{(\mathbf{t})}$ & $\mathbf{M n}_{\mathbf{( t )}}$ & $\mathbf{A l}^{\mathbf{3}^{+}}$ \\
\hline S1 (NA = 80) & 28,00 & 3,00 & 4,6 & 0,51 & 4,27 \\
S2 (NA = 40) & 0,50 & 0,50 & 0,03 & 0,69 & 0,02 \\
S3 (NA = 40) & 0,50 & 0,50 & 0,07 & nd & 0,19 \\
S4 (NA = 50) & 0,50 & 0,50 & 0,01 & nd & nd \\
S5 (NA = 40) & 3,00 & 1,00 & 0,03 & 0,03 & 0,14 \\
S6 (NA = 0) & 21,00 & 3,50 & 0,07 & 0,17 & Nd \\
S7 (NA =0) & 17,50 & 2,00 & 0,05 & 0,05 & 0,26 \\
\hline
\end{tabular}

Tabela 5 - Resultados analíticos $\left(\mathrm{mg}^{\left.-\mathrm{dm}^{-3}\right)}\right.$ de extração com água das amostras de lodo (L).

\begin{tabular}{c|c|c|c|c|c}
\hline Amostra & $\mathbf{N a}^{+}$ & $\mathbf{K}^{+}$ & $\mathbf{F e}_{(\mathbf{t})}$ & $\mathbf{M n}_{(\mathbf{t})}$ & $\mathbf{A l}^{3+}$ \\
\hline L8 & 16,00 & 1,30 & 0,03 & 0,10 & nd \\
L9 & 10,00 & 0,95 & 0,09 & 0,06 & nd \\
L10 & 3,00 & 1,00 & 0,15 & nd & 0,20 \\
L11 & 2,00 & 0,50 & 1,54 & 0,05 & 0,35 \\
L12 & 2,00 & 0,50 & 0,19 & 0,01 & nd \\
\hline
\end{tabular}

nd = não detectado

Tabela 6 - Resultados analíticos dos íons metálicos de interesse $\left(\mathrm{mg} \cdot \mathrm{dm}^{-3}\right)$ extraídos com $\mathrm{HNO}_{3}$

\begin{tabular}{c|c|c|c|c}
\hline Amostra & $\mathbf{A l}^{3+}$ & $\mathbf{F e}_{(\mathbf{t})}$ & $\mathbf{M n}_{(\mathbf{t})}$ & $\mathbf{H g}^{2+}$ \\
\hline S1 & 301,73 & 275,40 & 1,02 & 0,01 \\
S2 & 359,98 & 196,97 & nd & 0,01 \\
S3 & 359,70 & 248,93 & 1,00 & 0,01 \\
S4 & 318,00 & 277,00 & 2,33 & 0,01 \\
S5 & 196,65 & 216,89 & 0,75 & 0,01 \\
S6 & 503,00 & 268,93 & 1,39 & 0,02 \\
S7 & 538,74 & 384,95 & 2,36 & 0,03 \\
\hline
\end{tabular}

nd $=$ não detectado

Tabela 7 - Resultados de análises químicas de cátions $\left(\mathrm{mg}^{-\mathrm{dm}^{-3}}\right)$ das amostras de lodo (L) extração com $\mathrm{HNO}_{3}$.

\begin{tabular}{c|c|c|c|c}
\hline Amostra & $\mathbf{A l}^{3+}$ & $\mathbf{F e}_{(\mathbf{t})}$ & $\mathbf{M n}_{\mathbf{( t )}}$ & $\mathbf{H g}^{\mathbf{}}$ \\
\hline L8 & 279,00 & 282,97 & 1,67 & 0,06 \\
L9 & 348,00 & 347,91 & 2,12 & 0,03 \\
L10 & 426,80 & 387,85 & 8,95 & 0,02 \\
L11 & 112,65 & 101,46 & 0,62 & 0,06 \\
L12 & 398,00 & 384,81 & 5,56 & 0,04 \\
\hline
\end{tabular}

\section{Analises químicas das águas}

Os materiais sólidos bem como as soluções tiveram seus constituintes químicos analisados quantitativamente por espectrofotometria de absorção atômica (Perkin Elmer P-40 constituintes maiores e traço) fotometria de chama (Micronal B262 $-\mathrm{Na}^{+}$e $\mathrm{K}^{+}$) e por cromatografia iônica líquida (Dionex 2010i ânions).
Com a finalidade de se diminuírem os erros sistemáticos das análises, foram sempre realizadas determinações em paralelo.

A influência das impurezas dos reagentes, bem como das contaminações em geral e erros analíticos foram determinadas pelo uso de brancos os quais são também tomados como padrões de comparação nas técnicas espectrofotométricas. 
Os resultados das análises químicas dos principais cátions e anions das águas amostradas acham-se ilustrados nas tabelas 8 e 9 .

Nas águas naturais, diversos íons estão presentes em quantidades significativas o que obriga que se leve em conta a interação iônica da solução.
Por tratar-se de área de manguezal com aumento apreciável da força iônica (I), haverá diminuição dos coeficientes de atividade e maior será a solubilidade dos compostos presentes.

Com base na concentração dos íons em solução calcularam-se as forças iônicas para cada ponto (Tabela 10).

Tabela 8 - Resultados analíticos de cátions $\left(\mathrm{mg} \cdot \mathrm{dm}^{-3}\right)$ das amostras de água coletadas na área de estudo.

\begin{tabular}{c|c|c|c|c|c|c|c|c}
\hline Amostra & $\mathbf{H g}^{\mathbf{2 +}}$ & $\mathbf{N a}^{+}$ & $\mathbf{K}^{+}$ & $\mathbf{F e}$ & $\mathbf{\mathbf { M n } ^ { \mathbf { 2 } }}$ & $\mathbf{A l}^{\mathbf{3 +}}$ & $\mathbf{C a}^{\mathbf{2 +}}$ & $\mathbf{M g}^{\mathbf{2 +}}$ \\
\hline A0 & nd & 9,75 & 16,36 & nd & 0,33 & 1,43 & 5,92 & 0,98 \\
A1 & nd & 520,00 & 20,00 & 0,54 & 170,30 & 1,14 & 22,35 & 47,75 \\
A2 & $0,02.10^{-1}$ & 890,40 & 34,30 & nd & 210,00 & 8,00 & 28,90 & 108,90 \\
A3 & $0,03.10^{-1}$ & 6,70 & 4,80 & 0,58 & 90,60 & 0,65 & 9,00 & 1,95 \\
A4 & nd & 6,80 & 2,80 & 0,47 & 90,70 & 1,45 & 8,60 & 1,15 \\
A5 & nd & 190,00 & 6,80 & 0,73 & 115,80 & 7,70 & 16,60 & 15,80 \\
A6 & nd & 900,84 & 33,50 & 0,77 & 119,70 & 5,28 & 26,98 & 97,58 \\
A7 & nd & 892,30 & 35,90 & 0,89 & 113,40 & 6,13 & 43,84 & 85,98 \\
A8 & nd & 450,50 & 20,30 & 0,48 & 79,40 & 0,66 & 16,05 & 22,2 \\
A9 & nd & 520,76 & 18,60 & 0,54 & 76,50 & 2,04 & 34,63 & 23,64 \\
A10 & nd & 539,60 & 19,90 & 1,00 & 85,79 & 5,31 & 40,48 & 32,73 \\
\hline
\end{tabular}

nd = não detectado

Tabela 9 - Resultados analíticos de ânions $\left(\mathrm{mg}^{-\mathrm{dm}^{-3}}\right)$ das amostras de água.

\begin{tabular}{c|c|c|c|c|c|c|c}
\hline Amostra & $\mathbf{F}^{-}$ & $\mathbf{C l}^{-}$ & $\mathbf{N O}_{\mathbf{2}}^{-}$ & $\mathbf{B r}^{-}$ & $\mathbf{N O}_{\mathbf{3}}{ }^{-}$ & $\mathbf{P O}_{\mathbf{4}}{ }^{{ }^{-}}$ & $\mathbf{S O}_{\mathbf{4}}{ }^{{ }^{-}}$ \\
\hline A0 & 0,15 & 7,99 & n.d. & 0,015 & 0,16 & 0,63 & 1,92 \\
A1 & 0,75 & 375,83 & n.d. & 0,61 & 3,49 & 0,016 & 63,77 \\
A2 & 3,45 & 264,95 & n.d. & 0,95 & 4,28 & 0,04 & 46,73 \\
A3 & 0,17 & 10,87 & n.d. & 0,03 & 0,31 & 0,22 & 48,71 \\
A4 & 1,51 & 1061,3 & n.d. & 1,74 & 6,25 & 0,03 & 156,26 \\
A5 & 5,38 & 203,85 & n.d. & 1,58 & 6,23 & 0,11 & 43,78 \\
A6 & 7,09 & 3623,96 & n.d. & 9,47 & 8,27 & 0,28 & 721,84 \\
A7 & 2,75 & 1757,38 & n.d. & 4,11 & 0,18 & 0,07 & 378,44 \\
A8 & 1,37 & 651,15 & n.d. & 0,48 & 315,72 & 0,19 & 160,07 \\
A9 & 0,98 & 714,73 & n.d. & 0,71 & 205,65 & 0,13 & 149,74 \\
A10 & 0,49 & 235,9 & n.d. & 0,48 & 3,44 & 0,18 & 50,65 \\
\hline
\end{tabular}

nd $=$ não detectado

Tabela 10 - Valores de força iônica (I) calculados para águas (A) nos diferentes pontos de coleta.

\begin{tabular}{c|c}
\hline Ponto & $\left.\mathbf{I} \mathbf{~ 1 0}^{-3} \mathbf{( m o}\right)$ \\
\hline A0 & 1,2 \\
A1 & 29,1 \\
A2 & 43,4 \\
A3 & 5,3 \\
A4 & 21,9 \\
A5 & 15,7 \\
A6 & 100,0 \\
A7 & 66,9 \\
A8 & 30,2 \\
A9 & 33,3 \\
A10 & 22,2 \\
\hline
\end{tabular}

\section{DISCUSSÃO}

Qualquer composto mercurial seja ele orgânico ou inorgânico, pode ser gerado do mercúrio elementar. Neste estado é insolúvel na temperatura ambiente, no entanto, na presença de outras espécies químicas, sua capacidade de solubilização pode ser alterada consideravelmente.

A fixação de $\mathrm{Hg}^{\circ}$ é relativamente alta, no entanto sob condições aeróbias a ação de bactérias específicas faz com que passe para a forma iônica e tenha substancial incremento na sua capacidade de mobilização.

A forma segundo a qual o mercúrio vai se apresentar ou as transformações que poderá sofrer na busca da estabilidade, dependerá 
essencialmente das condições de $\mathrm{pH}$, do potencial e oxi-redução, concentração de ânions, tipo de sais presentes, natureza desses sais, solubilidade, tipos de solo/sedimento aos quais se acha associado e da matéria orgânica disponível para formar complexos estáveis .

O mercúrio pode ser encontrado na água, nas partículas em suspensão ou nos sedimentos.

No ambiente aquático o mercúrio pode ocorrer como $\mathrm{Hg}_{a q}^{0}, \mathrm{Hg}^{2+}$ e $\mathrm{Hg}_{2}^{2+}$, respectivas formas aquosas e ainda nas formas complexadas como p.e. $[\mathrm{HgOH}]^{+},[\mathrm{HgCl}]^{+}, \mathrm{HgCl}_{2},\left[\mathrm{HgCl}_{3}\right]^{-} \mathrm{e}$ $\left[\mathrm{HgCl}_{4}\right]^{2-}$.

Os padrões de qualidade ambiental segundo Resolução da Comissão Nacional do Meio Ambiente (CONAMA) n ${ }^{0}$ 20/86 estabelecem para as águas doces, o limite de $2.10^{-4} \mathrm{mg} \cdot \mathrm{dm}^{-3} \mathrm{e}$ 1. $10^{-4} \mathrm{mg} \cdot \mathrm{dm}^{-3}$ para as Classes 5 (salinas) e 7 (salobras).

Os padrões de potabilidade são estabelecidos em $2.10^{-3} \mathrm{dm}^{-3}$ (Decreto Federal $79637 \mathrm{de}$ 13/03/77) e $1.10^{-3}$ mg.dm ${ }^{-3}$ (Portaria 36). Para efluentes, a Resolução CONAMA 20/86, fixou para $\mathrm{o}^{\mathrm{Hg}^{2+}} \mathrm{o}$ teor de $0,01 \mathrm{mg} \cdot \mathrm{dm}^{-3}$.

Os resultados das análises granulométricas mostram predomínio acentuado de um sistema arenoso-siltoso pouco sujeito a adsorção; não se detectou mercúrio tanto no lodo como no sedimento.

Difratogramas dos diferentes pontos, como era de se esperar, dada a homogeneidade das amostras previamente analisadas, indicam a mesma composição mineralógica. Amostras de sedimentos e do lodo coletado nas margens do Rio Cubatão são constituídas essencialmente por caulinita $\quad\left(\mathrm{Al}_{2} \mathrm{Si}_{2} \mathrm{O}_{5}(\mathrm{OH})_{4}\right), \quad$ illita $\left(\mathrm{KAl}_{2}(\mathrm{Si}, \mathrm{Al})_{4} \mathrm{O}_{10}(\mathrm{OH})_{2} \cdot \mathrm{nH}_{2} \mathrm{O}\right)$ e gibbsita $\left(\mathrm{Al}(\mathrm{OH})_{3}\right)$, minerais com razoável poder de adsorção

Os íons associados aos sedimentos extraídos com água, pelos baixos teores obtidos, não apresentam qualquer interesse para este trabalho.

Os valores de $\Delta \mathrm{pH} \quad\left(\mathrm{pH}_{\mathrm{H} 2 \mathrm{O}}-\mathrm{pH}_{\mathrm{H} 2 \mathrm{O} / \mathrm{KCl}}\right)$ mostram a existência de valores negativos nas superfícies das partículas sólidas, que propicia adsorção de cátions.

Os resultados analíticos confirmam a presença estável do mercúrio metálico associado ao material sólido e sua inexistência ou presença em baixas concentrações nas águas.

É necessário lembrar que o ponto $\mathrm{A} 3$, onde se detectou maior teor de mercúrio, localiza-se nas imediações de uma indústria produtora de clorosoda, que preteritamente lançava efluentes de mercúrio nas margens do Rio Cubatão.

Os resultados mostram que o cloreto no ambiente dos estudos é uma contaminação natural nas águas. $\mathrm{Na}$ presença de $\mathrm{Cl}^{-}$, a quantidade de $\mathrm{Hg}^{2+}$ adsorvida por hidróxidos de ferro decresce, particularmente em baixos valores de $\mathrm{pH}$, formando $\mathrm{HgCl}^{+}, \mathrm{HgCl}_{2}{ }^{0}, \mathrm{HgCl}_{3}^{-}$e $\mathrm{HgCl}_{4}{ }^{2-}$ que são rapidamente adsorvidos na superfície dos hidróxidos (OBUKHOVSKAYA, 1982).

Podem ser observados os mais altos valores de força iônica na região característica de mangue (A6 e A7), o que leva a concluir que a elevada mobilidade do mercúrio também é resultado desta condição.

As águas assumem características diferentes em função dos pontos de coleta; desta forma, são classificadas como cloretadas sódicas em A6, A7 e A8, sulfocloretadas cálcicas em A3 e A4 e bicarbonatadas sódicas nos pontos A1 e A10.

Os resultados diferenciados para S1, S6, S7 e L8 principalmente para $\mathrm{o} \mathrm{Na}^{+}$são devidos às características desta porção da área de estudo, francamente representada por terrenos lodosos com águas salobras, onde se tem fenômenos de inundação do estuário influenciado pela oscilação das marés.

Por tratar-se de íons solúveis e de grande disponibilidade, os teores de sódio e potássio, foram extraídos com água e sua influência está relacionada à força iônica das soluções em contato com os materiais sólidos.

$\mathrm{O}$ manganês apresenta-se em baixas concentrações e, em relação ao mercúrio, tem o mesmo comportamento que ferro e alumínio.

Os resultados das análises químicas dos materiais submetidos à extração total com $\mathrm{HNO}_{3}$ apesar das concentrações relativamente baixas de $\mathrm{Hg}$ em relação a $\mathrm{Al}$ e $\mathrm{Fe}$, permitem, ao se projetarem os dados em diagrama triangular (FeAl-Hg, Tabela 11, Figura 2), estabelecer correlações entre eles. eles.

Tabela 11 - Teores de Al, Fe e Hg $\left(10^{4}\right)$ nos sedimentos (S) e lodos (L) calculados em porcentagem.

\begin{tabular}{l|c|c|c|c|c|c|c|c|c|c|c|c}
\hline & S1 & S2 & S3 & S4 & S5 & S6 & S7 & L8 & L9 & L10 & L11 & L12 \\
\hline Al & 44 & 55 & 51 & 46 & 39 & 52 & 45 & 24 & 35 & 42 & 14 & 34 \\
Fe & 41 & 30 & 35 & 40 & 42 & 28 & 31 & 24 & 35 & 38 & 12 & 32 \\
Hg.10 & 15 & 15 & 14 & 14 & 19 & 20 & 24 & 52 & 30 & 20 & 74 & 34 \\
\hline
\end{tabular}




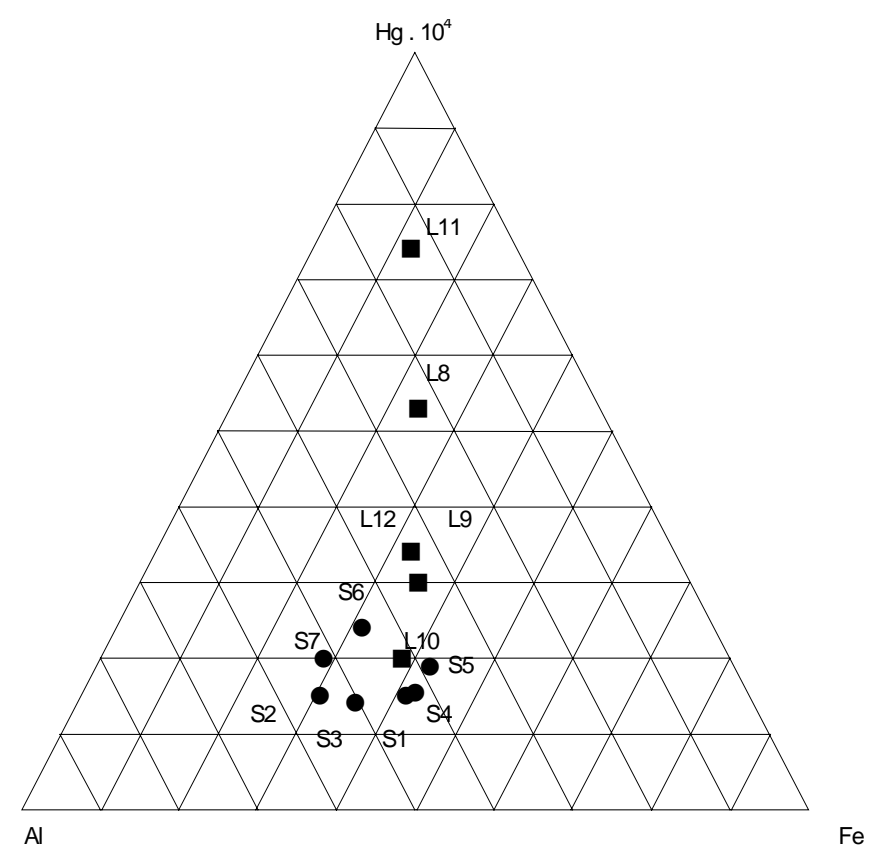

Figura 2 - Diagrama Triangular (Fe-Al-Hg) para as amostras de sedimentos (S) e lodos (L) da área de estudo.

\section{CONCLUSÕES}

A região de estudo está situada em uma área com interferência antrópica significativa, uma vez que está limitada pelo complexo industrial de Cubatão, pela área urbana, pelo Rio Cubatão onde são lançados efluentes, Rio Mogi onde são realizadas obras de aberturas de canais, além de estar próxima ao aterro sanitário da cidade.

As fontes difusas de emissão do mercúrio, como vazamentos na Baía de Santos, lançamento de efluentes no Rio Cubatão etc. são dificilmente individualizáveis, tornando imprópria a tomada de conclusões sobre a origem do mercúrio. Características do meio físico, como por exemplo a vegetação raquítica e existência de espécies invasoras, indicam degradação local.

Os terrenos locais são sedimentos arenosos e areno-siltosos com grande quantidade de matéria orgânica. A assembléia mineralógica é composta na maioria por quartzo, micas e fragmentos síltico-argilosos, associáveis aos gnaisses do Complexo Costeiro. Trata-se de sedimentos com grande concentração de finos, indicando fluxos unidirecionais, com interferência principalmente fluvial.

A presença de matéria orgânica e pirita imprimem um ambiente redutor aos sistemas estudados, com possibilidade do mercúrio encontrar-se estável sob a forma aquosa $\left(\mathrm{Hg}_{a q}^{0}\right)$ e/ou como sulfeto $(\mathrm{HgS})$. A projeção em diagrama $\mathrm{pH}=\mathrm{f}(\mathrm{Eh})$, para o sistema $\mathrm{Hg}-\mathrm{O}-\mathrm{H}-\mathrm{S}$ $\mathrm{Cl}$, mostra o $\mathrm{Hg}^{0}$ (aq) como a forma mais estável, o que lhe confere baixa capacidade de adsorção e significativa mobilidade. Se de um lado a formação de íons complexos entre $\mathrm{Hg}^{2+} \mathrm{e}$ principalmente $\mathrm{Cl}^{-}$propicia alta mobilidade, de outro, essas cargas podem ser fator de adsorção por partículas componentes do mangue. Cabe ressaltar ainda pelo diagrama $\mathrm{pH}=\mathrm{f}$ (Eh) que com variações mínimas na concentração do mercúrio, pode-se atingir o campo de estabilidade do $\mathrm{HgS}$.

Os resultados analíticos para sólidos distinguem os sedimentos do manguezal de lodos provenientes das margens do Rio Cubatão. O mercúrio apresenta concentrações e mobilidade diferenciadas para cada um desses sistemas.

As partículas com tamanhos coloidais associadas aos argilominerais, predominantemente caulinita e gibbsita, encontram-se carregadas negativamente $(\Delta \mathrm{pH}$ maior que zero) o que propicia adsorção de íons metálicos.

A maior adsorção do mercúrio está associada ao aumento dos teores de compostos (óxidos e hidróxidos) de ferro, alumínio e manganês e matéria orgânica nos sedimentos. Neles, os teores iônicos principalmente de sódio e potássio, bastante elevados, contribuem significativamente para a elevação da força iônica local, agindo de forma a promover a mobilização do mercúrio. 
A saturação em água nos lodos é o veículo e o componente que mais influi na mobilidade do mercúrio, quando comparados com sedimentos.

Nos sedimentos o mercúrio acha-se associado à matéria orgânica e pouca influência têm os óxido-hidróxidos presentes, evidenciado no diagrama triangular $(\mathrm{Hg} / \mathrm{Fe} / \mathrm{Al})$. Os eletrólitos contribuem notadamente para sua mobilização nos locais sujeitos às variações da maré.
Nos lodos não se observou influência da força iônica e matéria orgânica, sendo a importância dos óxidos-hidróxidos bastante evidenciada na adsorção do mercúrio.

Nos lodos coletados nas margens dos rios Cubatão e Mogi, pode-se desconsiderar a influência de eletrólitos e assim a concentração de ferro e alumínio tem influência decisiva na fixação do mercúrio.

\section{REFERÊNCIAS}

CETEM- Centro de Tecnologia Mineral. Projeto Poconé. Relatório Anual. 210p. Rio de Janeiro, 1989.

CETESB. Mapeamento dos ecossistemas costeiros do Estado de São Paulo. (Coord. LAMPARELLI, C.C.; MOURA, D.O). Ed. Páginas \& Letras. 108p. São Paulo, 1998.

CONAMA - Resolução Conama $\mathbf{N}^{\mathbf{0}}$ 20. 1986. Publicado no D.O.U. de 30/07/86, 1986.

HYPOLITO, R. Geoquímica da Interação solo/rocha/água (GGE-5817)- Curso de PósGraduação - Programa de Recursos Minerais e Hidrogeologia. CEPAS- IGc-USP. Texto Didático, 87 p. 2004.

KAISER, R.; TÖLG， G. Handbook of environmental chemistry. Parte A. New York. Springer Verlag. v 3, 1980.

KOTHNY, E.L. The three phase equilibrium of mercury in the nature. Advance in Chemistry Series,123p, p49-80, 1993.

LINDQVIST, O.; RHODE, H. Atmospheric mercury: a review. Ed. Tellus, v37B. 67p, 1985. MASTER, H.B. Mining Annual Review, C85C87, 1989.

NIAGRU, J.O. Global metal pollution poisoning the biosphere? Environment. $\mathrm{n}^{\circ}$ 32. p 7- 33, 1990.
OBUKHOVSKAYA, T.D. Mercury sorption by soil minerals. Traduzido de Pochvovedeniey. Soviet Soil Science. Scripta Publishing. U.S.A. v14 (3). p 49-55, 1982.

REEDER, S.W.;DEMAYO, A.; TAYLOR, M.C. Mercury. Guidelines for surface water quality inorganic chemical substances. Environment Canada, Ottawa, 15p, 1979.

SÃO PAULO (Estado). Instituto Geográfico e Cartográfico. Folha Topográfica Cubatão. São Paulo, IGC.,1987. (Escala 1: 10.000).

SCHROEDER, W.H.; SCHNEEBERGER, D.R. High-temporal-resolution measurements of total gaseous mercury in air at Alert, Northwest Terrotories, Canada. Hamburg. In: Fourth International Conference on Mercury as a Global Polluant. Book of abstracts. GKSSForschungszentrum Geesthatch \& Oak Ridge National laboratory. 128p, 1996.

WILKEN, R.D.; HINTELMANN, H. Analysis of mercury- species in sediments. In: Metal Specification in the Environment, NATO ASI Series, Ed. J.A.C. Broekaert, S. Gücer and F. Adams. v.G23. p339-359, 1990. 